\title{
Association Between Physical Activities and Menopausal Symptoms Among Menopausal Women
}

\author{
Laila Mohammad Nuwigi Alrashidi ${ }^{1}$, Sahar Ahmed Ali Al Shamandy ${ }^{1,}$, \\ Haifa Abdul-Aziz Al-Turki ${ }^{2}$ \\ ${ }^{1}$ Obstetrics and Gynecology Nursing, College of Nursing, Imam Abdulrahman Bin Faisal University, Dammam, Saudi Arabia \\ ${ }^{2}$ Obstetrics \& Gynecology Medicine, College of Medicine, Imam Abdulrahman Bin Faisal University, Dammam, Saudi Arabia
}

\section{Email address:}

salshamandy@iau.edu.sa (S. A. A. Al Shamandy)

${ }^{*}$ Corresponding author

\section{To cite this article:}

Laila Mohammad Nuwigi Alrashidi, Sahar Ahmed Ali Al Shamandy, Haifa Abdul-Aziz Al-Turki. Association Between Physical Activities and Menopausal Symptoms Among Menopausal Women. American Journal of Nursing Science. Vol. 8, No. 6, 2019, pp. 294-303. doi: 10.11648/j.ajns.20190806.12

Received: September 6, 2019; Accepted: September 28, 2019; Published: October 20, 2019

\begin{abstract}
Menopause play a vital role in woman's life. Recent study emphasized that physical activities are becoming one of the most important alternative treatments to deal with menopausal symptoms. This study aims to determine the association between level of physical activities and menopausal symptoms among women. A cross sectional study design was used in carrying out this study. The study conducted at King Fahad Hospital of University (KFHU) in its Outpatient Department (OPD) from March to May 2018 with a total sample of 208 women who visiting the previous mentioned setting according to the inclusion criteria. Three tools were used to collect data: A structured questionnaire sheet was developed and used by the researcher after reviewing the related literatures to collect socio-demographic data. A standardized tool (Menopausal Rating Scale-MRS) was used to know the prevalence and severity of menopausal symptoms and a standardized tool (Leisure-Time Exercise Questionnaire-LTEQ) was used to assess physical activities intensity. The results of the present study revealed that more than half of the participants had moderate level of the severity of menopausal symptoms (53.4\%). This study also shows that the $(82 \%)$ of them were more likely to do only mild exercise and only two symptoms namely hot flush/sweating from somatic symptoms and depressive mood under psychological symptoms demonstrated statistical significance with $\mathrm{p}$ values $0.002 \& 0.029$ respectively. Also, it is observed in this study that Body Mass Index (BMI) and the menopausal symptoms which comes under the somatic symptoms provides a high statistical significance with $\mathrm{p}$ value of 0.001 . The study signifies that more than half of menopausal women (53.4\%) were in the normal menopausal age and most women with a normal BMI $(69.2 \%)$. While signifies the prevalence of joint and muscular discomfort was the highest among the four somatic menopausal symptoms with $95.2 \%$ of participants, followed by bladder problems was the highest among urogenital subscales with (88.5\%). However, the physical and mental exhaustions was the highest among psychological subscales with $84.1 \%$ of the participants.
\end{abstract}

Keywords: Physical Activities, Menopausal Symptoms, Menopausal Women

\section{Introduction}

Menopause is the stage of transition in a women's active reproductive life with normal menstrual period towards the cessation of menstruation (amenorrhea) or it is the mere absence of menstrual period for 12 months without any noticeable causes. It is not an abrupt cessation of menstruation, but there exists a clear transitional period with a varying menstrual phase, which gradually leads to the cessation of periods. There is a perimenopause stage, often called "the time around menopause", which is referred to as the transitional stage of menopause, where the last periods will be regular with increased levels of Follicle Stimulating Hormone (FSH). When the women attain the stage of menopause the functions of the female gonads or ovaries terminates, leading to the cessation of reproductive life, where the women cannot become pregnant [1].

Menopause is also a period characterized by metabolic, 
hormonal and clinical changes, caused by the progressive decline in ovarian activity and it may also lead to psychosocial alterations. It indicates the aging process in women, and it occurs on average age between 45 to 55 years [2]. The different stages of menopause is well defined in the executive summary of the Stages of Reproductive Aging Workshop, where menopause is categorized into three stages, the pre-menopause, which is the late reproductive phase followed by perimenopause, which is the early and late menopausal transition leading to post-menopause, whose individualization and duration are not linear, where the last phase is characterized by high FSH levels with a decline in serum estradiol [3]. The hormonal changes during menopause and its consequent alterations in the levels of sex hormones leads to the cessation of regular menstrual period are accompanied by unwelcome symptoms. The epidemiological studies estimated that as many as $85 \%$ of postmenopausal women have experienced a menopause related symptom in their lifetime [4]. (Kim, Yim and Park 2018). Even though many women experience several symptoms of menopause, these symptoms are reported to be augmented with early menopause. The woman during menopausal age is associated with numerous physical, vasomotor, psychological, and sexual complaints, not only experience results the termination of reproductive function [5]. Another study from Kim et al, (2014) [6]. indicates that many symptoms occurs more frequently during this period including night sweats, hot flushes, vaginal dryness, depression, irritability, headache, and sleep disturbance.

According to Stojanovska (2014) [7]. emphasis on hormone replacement therapy is effective in improving symptoms. Its side effects have been reported which has resulted in alternative choices for treatment. Also, this study stated that another alternative choice for treatment is exercise for relieving menopausal symptoms which includes psychological, vasomotor, somatic and sexual symptoms. The Physical Activity Guidelines Advisory Committee in 2008 [8]. Reported there are numerous health benefits when physical activity initiated during this period including a scale down danger of heart problem, metabolic syndrome, overweight, cancer, depression and osteoporosis. Also, there is confirmation that physical activity may be effective in stopping or reducing menopausal symptom [6].

Numerous previous studies showed reduces menopausal symptoms significantly when doing physical activity $[9,10]$ but some other studies have found that it improves both physical and psychosocial symptoms, when physical activity is continued but it does not significantly influence symptoms, specifically vasomotor and sexual symptoms [11, 12]. In addition, few studies stated that high physical activity level is associated with less climacteric symptoms and continuity in normal physical activity at least one hour per day presented positive relationship for the prevention of menopausal symptoms [13, 14]. Another study from midlife women in multi-ethnic groups stated that severity and prevalence of menopausal symptoms are significantly influenced by specific type of physical activity performed by women, which was changed by ethnicity [15]. There have been some differences regarding between menopausal symptoms and exercise however evidences strongly support physical activity as beneficial for menopausal symptoms.

There are several studies across the globe investigating the effect of physical activity and its role in reducing menopausal symptoms. A randomized control study assessed the effect of exercise and nutrition education on quality of life and early menopausal symptoms and they concluded that nutrition education with aerobic exercise can improve quality of life and reduce early menopause symptoms [16].

Moreover, a cross sectional study assessed the association between demographic and lifestyle parameters and perceived severity of the climacteric syndrome in perimenopausal women. The authors concluded with the findings that regular exercise of at least three times a week was the most significant lifestyle parameter to be associated with the severity of climacteric symptoms. Further, endurance exercise and its effect on menopausal symptoms was studied among in Nigerian women, which observed significant changes in quality of life and back pain and recommended routine participation in endurance exercise programs [17]. Yet another study which was designed to determine the effects of different short-term exercise programs on menopausal symptoms, psychological health, and quality of life in postmenopausal women concluded that resistance exercise and aerobic exercise were found to have a positive impact on menopausal symptoms, psychological health, depression, and quality of life [1]. (Ag1l et al., 2010).

Significant of the study:

There are limited studies exploring precisely the influence of physical activity and its effect on reducing the climacteric symptoms among the women in the Kingdom of Saudi Arabia. Hence this research is intended to investigate the association between physical activities and menopausal symptoms among menopausal women in Al-Khobar CityEastern Province of Saudi Arabia. This in turn will draw the attention to the health care provider to provide help, guidance and health education to those women. In addition, to prevent problems that might be happen from inappropriate interventions by the women to overcome the severity of menopausal symptoms that may cause dangerous health problems for them. Consequently, the women health will be maintained, and daily life routine will be carried out well, especially for women who are complaining from severe menopausal symptoms. It is also important for menopausal women to recognize the importance of physical activity during this period.

\section{Aim of the Study}

The present study aims to determine the association between level of physical activities and menopausal symptoms among women. 


\section{Research Questions}

1. What are the actual prevalence and severity of menopausal symptoms among women?

2. What is the level of physical activities among menopausal women?

3. Are there any statistical associations between menopausal symptoms and level of physical activities and other variables?

\section{Methods}

\subsection{Research Design}

A cross sectional study design was used in carrying out this study to answer the research questions.

\subsection{Research Setting}

This study was conducted at King Fahad Hospital of University (KFHU) in its Outpatient Department (OPD). This hospital located in Al-Khobar City- Eastern Province of Saudi Arabia. It serves many people who seeks medical care. The rationale for selecting this setting is the high utilization of the KFHU services by menopausal women who are seeking health care in OPD.

\subsection{Sample}

This study was conducted from March to May 2018 with a total sample of 208 women who visiting the previous mentioned setting according to the inclusion criteria.

\subsubsection{Sample Size Calculation}

$$
\text { Formula }(\mathrm{n})=\frac{Z^{2}}{d^{2}} \mathrm{pq}
$$

Where $\mathrm{z}^{2}=1.96, \mathrm{~d}^{2}=$ precision level

Prevalence rate (rate of exercise during menopausal) (pilot study outcome $)=\mathrm{p}=11 \%=0.11$, and $\mathrm{q}=0.89$

Therefore, $\mathrm{n}=\left(1.96^{2} / 0.002\right) * 0.11 * 0.89$

$\mathrm{n}=188.04$

Hence, the study included a total of 200 sample (rounded figure).

\subsubsection{Inclusion Criteria}

1. Women experiencing menopause naturally (No menstrual period for at least 12 consecutive months).

2. Women with frequent menopausal symptoms.

\subsubsection{Exclusion Criteria}

1. Women using hormone replacement therapy (HRT) or over-the counter medications to treat menopausal symptoms before two months.

2. Women with surgical menopause (Hysterectomy)

3. Women who receiving chemotherapy (or radiotherapy) for any type of cancer.

\subsection{Data Collection Tool}

The data collection consisted of three tools: Socio- demographic data, Menopausal Rating Scale (MRS) and the Leisure-Time Exercise Questionnaire (LTEQ).

Tool I. A structured questionnaire sheet was developed and used by the researcher after reviewing the related literatures to collect socio-demographic data from the participating women. It included, age of the participants, their height, weight, BMI, educational qualification, marital status and occupation.

Tool II. A standardized tool (Menopausal Rating ScaleMRS) which was developed and validated by Heinemann. L (1990) [17, 18] Ogwumike OO, Sanya AO, Arowojolu AO. (2011). Endurance exercise effect on quality of life and menopausal symptoms in Nigerian women. Afr J Med Med Sci. 40 (3): 187-95. was used to know the prevalence and severity of menopausal symptoms which was developed by the Berlin Center for Epidemiology and Health Research in 1990 and approval to use this scale has been taken from Prof. Dr. Lothar A. J. Heinemann. In addition, the MRS was primarily published in German, and the first translation was from German to English followed by translation into other languages and became internationally accepted. Unfortunately, there was no Arabic version, and for the purpose of this research, English version was used and was translated into Arabic, and then back to English for validation.

According to Heinemann L. (1990) [18], this scale consists of eleven items. Each item is scored on a Likert scale of zero to four, with response categories of: $(0=$ not present, $1=$ mild, $2=$ moderate, $3=$ severe and $4=$ very severe). The total score calculated according to MRS and the severity of symptoms categorized as follows:

1. No or mild symptoms $=0-11$ score.

2. Moderate symptoms $=12-22$ score.

3. Severe or very severe symptoms $=23-44$ score.

The eleven items in MRS were arranged with three categories as the following:

1) Somatic symptoms: It includes: hot flushes, heart discomfort, sleep problems and joint and muscular discomfort (items 1-3 and 11).

2) Psychological symptoms: It includes: depressive mood, irritability, anxiety and physical \& mental exhaustion (items 4-7, respectively).

3) Urogenital symptoms: It includes: sexual problems, bladder problems, and dryness of vagina (items 8-10, respectively).

Tool III. A standardized tool (Leisure-Time Exercise Questionnaire-LTEQ) which was developed and validated by Godin G, Shephard RJ. (1985) [9]. This tool was used to assess physical activities intensity and was explored as mild, moderate and strenuous intensity exercise activity performed during free time for more than 15 minutes of an average of 7 days' period. The intensity of physical activities determined according to LTEQ and the level of physical activities categorized as follows:

a) Mild exercise: It is minimal effort example like: yoga, archery, fishing from river bank, bowling, horseshoes, golf, and easy walking. 
b) Moderate exercise It is not exhausting example like: fast walking, baseball, tennis, easy bicycling, volleyball, badminton, easy swimming, alpine skiing, popular and folk dancing.

c) Strenuous exercise It is happening heart beats rapidly example like: running, jogging, hockey, football, soccer, squash, basketball, cross country skiing, judo, roller skating, vigorous swimming, vigorous long-distance bicycling. All data collection tools were used translated into Arabic language and then back to English for validation.

\subsection{Reliability Analysis: Pilot Study Outcomes $(n=30)$}

Reliability Statistics showed the value of Cronbach's Alpha coefficient for the whole scale as 0.808 , which is an excellent internal consequence of the validity of this questionnaire. In addition, the reliability for the sub scales ranging from 0.721 to 0.810 . Based on these measures, we can conclude that this tool is reliable and valid for measuring Physical Activities Effect on Menopausal Symptoms.

\subsection{Procedures}

Across sectional study was carried out at King Fahad Hospital of University (KFHU) in Al-Khobar City located in the Eastern Province of Saudi Arabia in its Outpatient Department. The data were collected between March and May 2018 with total sample equal two hundred eight menopausal women who defined by no menstrual period for at least 12 consecutive months and met the inclusion criteria and attended the hospital during this period for follow up their clinics.

The study was approved by the ethical committee of Deanship of Scientific Research/ Institutional Review Board (IRB) of Imam Abdulrahman Bin Faisal University and Written official permissions to conduct this study were obtained from the concerned authorities after explanation of the research methodology.

The data collection tool was checked and pretested for clarity and suitability in a small pilot study of 30 women who met the inclusion criteria. The necessary modifications were made, and menopausal women in the pilot study were not included in the total sample.

The researcher explained the aim of this study and the procedures to every woman who meet the inclusion criteria and then written informed consent was obtained from participants in this study and confidentiality of information will be assured to ensure honest response.

The interviews were performed to every woman at one session for duration of 15-20 minute for each woman by using convenient method of sampling. The researcher collected the demographic data from the participants and asked the women to answer all questions related to MRS and LTEQ to assess their menopausal symptoms and level of physical activities.

\subsection{Data Analysis}

All categorical data were presented by frequency with percentage, and continuous data were presented by mean $\&$ standard deviation. Association between menopausal symptoms and physical activities was tested by using chisquare test. Also, the relationship between the demographics data and menopausal symptoms was tested by independent $t$ test and ANOVA technique. All the analysis was done by using SPSS 21.0 version. A p value less than 0.05 were considered as significant.

\section{Results}

Table 1: A total of 208 menopausal women were included in this study. Among the sampled participants, table 1 illustrates the socio-demographic factors of participants included: the mean age of the participants was $61.7 \pm 8.9$. However, more than half of women $(53.4 \%)$ were in the normal menopausal age with mean of menopausal age is 47.7 $(\mathrm{SD} \pm 4.5)$. The same table shows that most women with a normal BMI (69.2\%). The educational level of women indicates that less than half of them $(41.3 \%, 60.6 \%)$ were illiterates were housewives respectively. Also, the table revels that $16.8 \%$ of women were past smokers and a minority of them consumes alcohol $(2.4 \%)$ according to their life style. The study also considered the dietary pattern of participants which indicates that $91.3 \%$ of them eating fresh fruits and vegetables and the majority (78.8\%) consumes low fat diet, followed by consumption of beverages indicating that $71.6 \%$ consumes tea or coffee.

Table 1. Distribution of Socio-Demographic Characteristics among Menopausal Women.

\begin{tabular}{|c|c|c|}
\hline \multirow{2}{*}{$\begin{array}{l}\text { Demographic Characteristics of Menopausal Women } \\
\text { Age in years. }\end{array}$} & \multicolumn{2}{|l|}{ Number of Participants $=\mathbf{2 0 8}$} \\
\hline & & \\
\hline Mean \pm SD & $61.7 \pm 8.9$ & \\
\hline Minimum - Maximum & $43-87$ & \\
\hline Age at menopause, & $\mathrm{N}$ & $(\%)$ \\
\hline Early menopause (41-45 yrs. old) & (87) & $41.8 \%$ \\
\hline Normal menopause (46-55 yrs. old) & (111) & $53.4 \%$ \\
\hline Late menopause (over the age of 55). & $(10)$ & $4.8 \%$ \\
\hline Mean \pm SD & $47.7 \pm 4.5$ & \\
\hline Minimum - Maximum & 38 yrs. -59 yrs. & \\
\hline BMI & $\mathrm{n}$ & $(\%)$ \\
\hline Underweight $(<18.50)$ & (5) & $2.4 \%$ \\
\hline Normal (18.50 - 24.99) & (144) & $69.2 \%$ \\
\hline Overweight $(\geq 25.00)$ & $(46)$ & $22.1 \%$ \\
\hline Obese $(\geq 30.00)$ & (13) & $6.3 \%$ \\
\hline
\end{tabular}




\begin{tabular}{|c|c|c|}
\hline Demographic Characteristics of Menopausal Women & Number of Participants $=208$ & \\
\hline Nationality & $\mathrm{n}$ & $(\%)$ \\
\hline Saudi & (161) & $77.4 \%$ \\
\hline Non-Saudi & (47) & 22.6( \\
\hline Marital status & $\mathrm{n}$ & $(\%)$ \\
\hline Single & (4) & $1.9 \%$ \\
\hline Married & (143) & $69.1 \%$ \\
\hline Widow & $(51)$ & $24.6 \%$ \\
\hline Divorced & (9) & $4.3 \%$ \\
\hline Educational level & $\mathrm{n}$ & $(\%)$ \\
\hline Illiterate & (86) & $41.3 \%$ \\
\hline Primary School & (41) & $19.7 \%$ \\
\hline Intermediate school & (32) & $15.4 \%$ \\
\hline High school & (27) & $13.0 \%$ \\
\hline University or higher & (22) & $10.6 \%$ \\
\hline \multicolumn{3}{|l|}{ Women Life style: } \\
\hline Occupation & $\mathrm{n}$ & $(\%)$ \\
\hline Employed & $(62)$ & $29.8 \%$ \\
\hline Housewife & (126) & $60.6 \%$ \\
\hline Retiree & (20) & $9.6 \%$ \\
\hline Alcohol use & $\mathrm{n}$ & $(\%)$ \\
\hline Yes & (5) & $2.4 \%$ \\
\hline No & (203) & $97.6 \%$ \\
\hline Smoking & $\mathrm{n}$ & $(\%)$ \\
\hline Never & (166) & $79.8 \%$ \\
\hline Past smoker & (35) & $16.8 \%$ \\
\hline Current smoker & (7) & $3.4 \%$ \\
\hline Eating fresh fruits and vegetables & $\mathrm{n}$ & $(\%)$ \\
\hline Yes & $(190)$ & $91.3 \%$ \\
\hline No & $(18)$ & $8.7 \%$ \\
\hline Eating low fat diet & $\mathrm{n}$ & $(\%)$ \\
\hline Yes & (164) & $78.8 \%$ \\
\hline No & (44) & $21.2 \%$ \\
\hline Tea /coffee consumption & $\mathrm{n}$ & $(\%)$ \\
\hline Yes & (149) & $71.6 \%$ \\
\hline No & $(59)$ & $28.4 \%$ \\
\hline
\end{tabular}

Table 2: The prevalence of menopausal symptoms according to MRS were rated from no symptoms to extremely severe. Table 2 shows nearly less than half of the participants $(45.7 \%)$ had mild hot flush/sweating symptoms, whereas $38.9 \%$ reported mild heart discomforts under the somatic symptoms. Moreover, among the psychological symptoms, mild depressive mood symptoms were reported by $39.9 \%$. Irritability symptom was almost equally reported at mild and moderate level $(32.2 \%$ \& $34.1 \%$ respectively).
Anxiety symptoms also provided almost the same distribution with no symptoms, mild and moderate symptoms $(34.6 \%$ \& $33.2 \%$ \& $29.3 \%$ respectively). Regarding urogenital symptoms, sexual problems were reported extremely severe by $10.1 \%$. Moderate symptoms of urinary bladder related problems were reported by $49.5 \%$ of the participants, however, $25.4 \%$ of them reported mild symptoms of vaginal dryness.

Table 2. Prevalence of Menopausal Symptoms According to Menopausal Rating Scale (MRS).

\begin{tabular}{|c|c|c|c|c|c|c|}
\hline \multirow{2}{*}{ Categories } & \multirow{2}{*}{ Menopausal Symptoms } & \multicolumn{5}{|c|}{ Menopause Rating Scale $($ MRS) $(\mathrm{n}=\mathbf{2 0 8})$} \\
\hline & & None (0) & Mild (1) & Moderate (2) & Severe (3) & Extremely severe (4) \\
\hline \multirow{4}{*}{ Somatic symptoms } & Hot flush \& sweating & (89) $42.8 \%$ & (95) $45.7 \%$ & (24) $11.5 \%$ & 0 & 0 \\
\hline & Heart discomfort & (86) $41.3 \%$ & (81) $38.9 \%$ & (38) $18.3 \%$ & (1) $0.5 \%$ & (2) $1.0 \%$ \\
\hline & Sleep problems & (46) $22.2 \%$ & (81) $38.9 \%$ & (67) $32.2 \%$ & (14) $6.7 \%$ & 0 \\
\hline & $\begin{array}{l}\text { Joint \& muscular discomfort } \\
\text { Mean } \pm \text { SD } 1.12 \pm 0.5\end{array}$ & (10) $4.8 \%$ & (54) $26.0 \%$ & (113) $54.3 \%$ & (31) $14.9 \%$ & 0 \\
\hline \multirow{4}{*}{ Psychological symptoms } & Depressive mood & (43) $20.7 \%$ & (83) $39.9 \%$ & (77) $37.0 \%$ & (5) $2.4 \%$ & 0 \\
\hline & Irritability & (66) $31.8 \%$ & (67) $32.2 \%$ & (71) $34.1 \%$ & (4) $1.9 \%$ & 0 \\
\hline & Anxiety & (72) $34.6 \%$ & (69) $33.2 \%$ & (61) $29.3 \%$ & (6) $2.9 \%$ & 0 \\
\hline & $\begin{array}{l}\text { Physical \& mental exhaustion } \\
\text { Mean } \pm \text { SD } 1.18 \pm 0.6\end{array}$ & (33) $15.9 \%$ & (71) $34.1 \%$ & (74) $35.6 \%$ & (30) $14.4 \%$ & 0 \\
\hline \multirow{4}{*}{ Urogenital symptoms } & Sexual problems & (100) $48.2 \%$ & (40) $19.2 \%$ & (34) $16.3 \%$ & (13) $6.2 \%$ & (21) $10.1 \%$ \\
\hline & Bladder problems & (24) $11.5 \%$ & (55) $26.4 \%$ & (103) 49.5\% & (23) $11.1 \%$ & (3) $1.5 \%$ \\
\hline & Vaginal dryness & (103) $49.5 \%$ & (53) $25.4 \%$ & (38) $18.3 \%$ & (11) $5.3 \%$ & (3) $1.5 \%$ \\
\hline & Mean \pm SD $1.18 \pm 0.7$ & & & & & \\
\hline
\end{tabular}


Table 3: The data was also explored for the proportion of those menopausal symptoms as illustrated in table 3 and it is observed that the proportion of the symptom of joint and muscular discomfort was the highest among the somatic menopausal symptoms with $95.2 \%$ of participants, followed by bladder problems was the highest among urogenital symptoms with $88.5 \%$. However, the physical and mental exhaustions was the highest among psychological symptoms with $84.1 \%$ of the participants, followed by depressive mood (79.3\%), sleep problems (77.8\%) and irritability (68.2\%).

Table 3. Proportion of Menopausal Symptoms among Participant.

\begin{tabular}{|c|c|c|c|}
\hline Categories & Menopausal symptoms & Percentage without symptoms & Percentage with symptoms \\
\hline \multirow{4}{*}{ Somatic symptoms } & Hot flush, sweating & (89) $42.8 \%$ & (119) $57.2 \%$ \\
\hline & Heart discomfort & (86) $41.3 \%$ & (122) $58.7 \%$ \\
\hline & Sleep problems & (46) $22.2 \%$ & (162) $77.8 \%$ \\
\hline & Joint \& muscular discomfort & (10) $4.8 \%$ & (198) $95.2 \%$ \\
\hline \multirow{3}{*}{ Psychological symptoms } & Depressive mood & (43) $20.7 \%$ & (165) $79.3 \%$ \\
\hline & irritability & (66) $31.8 \%$ & (142) $68.2 \%$ \\
\hline & Anxiety & (72) $34.6 \%$ & (136) $65.4 \%$ \\
\hline \multirow{3}{*}{ Urogenital symptoms } & Sexual problems & (100) $48.1 \%$ & (108) $51.9 \%$ \\
\hline & Bladder problems & (24) $11.5 \%$ & (184) $88.5 \%$ \\
\hline & Vaginal dryness & (103) $49.5 \%$ & (105) $50.5 \%$ \\
\hline
\end{tabular}

Table 4: In the analysis of table 4 that signifies the severity of menopausal symptoms based on MRS. It is observed that under the somatic symptoms, $14.9 \%$ of the participants reported severe to very severe joint $\&$ muscular discomfort, which indicate that this symptom was the highest and the most common reported menopausal symptom. When the psychological symptoms are analyzed, it is observed that participants under severe to very severe category were small, but the physical symptom and mental exhaustion was observed to be higher $(14.4 \%)$ than the other three symptoms. Regarding the urogenital symptoms, table 4 illustrates that sexual problems was reported as severe to very severe condition for $16.3 \%$ of participants followed by Bladder problems (12.6\%).

Table 4. Severity of Menopausal Symptoms among Participant.

\begin{tabular}{lllll}
\hline Categories & Menopausal symptoms & None - Mild & Moderate & Severe - very severe \\
\hline \multirow{5}{*}{ Somatic symptoms } & Hot flush, sweating & $(184) 88.5 \%$ & $(24) 11.5 \%$ & 0 \\
& Heart discomfort & $(167) 80.2 \%$ & $(38) 18.3 \%$ & $(3) 1.5 \%$ \\
& Sleep problems & $(127) 61.1 \%$ & $(67) 32.2 \%$ & $(14) 6.7 \%$ \\
& Joint \& muscular discomfort & $(64) 30.8 \%$ & $(113) 54.3 \%$ & $(31) 14.9 \%$ \\
& Depressive mood & $(126) 60.6 \%$ & $(77) 37.0 \%$ & $(5) 2.4 \%$ \\
\multirow{5}{*}{ Psychological symptoms } & Irritability & $(133) 64.0 \%$ & $(71) 34.1 \%$ & $(4) 1.9 \%$ \\
& Anxiety & $(141) 67.8 \%$ & $(61) 29.3 \%$ & $(6) 2.9 \%$ \\
& Physical \& mental exhaustion & $(104) 50.0 \%$ & $(74) 35.6 \%$ & $(30) 14.4 \%$ \\
Urogenital symptoms & Sexual problems & $(140) 67.4 \%$ & $(34) 16.3 \%$ & $(34) 16.3 \%$ \\
& Bladder problems & $(79) 37.9 \%$ & $(103) 49.5 \%$ & $(26) 12.6 \%$ \\
\hline
\end{tabular}

Table 5: Furthermore, the menopausal symptoms were evaluated according to the level of physical activity of the participants. The table 5 shows that out of the 208 participants of the study, $(82 \%)$ of them were more likely to do only mild exercise and only two symptoms namely hot flush/sweating under somatic symptoms and depressive mood under psychological symptoms demonstrated statistical significance with $\mathrm{p}$ values $=0.002 \& 0.029$ respectively. However, there was no statistical significance differences between the remaining symptoms and the level of physical activities.

Table 5. Relationship between Menopausal Symptoms \& Level of Physical Activities.

\begin{tabular}{lllll}
\hline \multirow{2}{*}{ Menopausal Symptoms } & \multicolumn{2}{l}{ Level of Physical Activities } & \multirow{2}{*}{ Chi-Square Test } & P-Value \\
\cline { 2 - 3 } & Mild n=170 (82\%) & Moderate n=38 (18\%) & & $0.002^{*}$ \\
\hline Somatic symptoms: & $(105) 61.8 \%$ & $(13)) 34.2 \%$ & 9.606 & 0.135 \\
Hot flush, sweating & $(103) 60.6 \%$ & $(18) 47.4 \%$ & 2.231 & 0.300 \\
Heart discomfort & $(134) 78.8 \%$ & $(27) 71.1 \%$ & 1.072 & 0.119 \\
Sleep problem discomfort & $(163) 95.9 \%$ & $(34) 89.5 \%$ & 2.547 & $0.029 *$ \\
Joint \& muscle & & & & 0.926 \\
Psychological symptoms: & $(139) 81.8 \%$ & $(25) 65.8 \%$ & 0.752 & 0.380 \\
Depressive mood & $(115) 67.6 \%$ & $(26) 68.4 \%$ & 0.772 & 0.385 \\
Irritability & $(108) 63.5 \%$ & $(27) 71.1 \%$ & 0.753 & \\
Anxiety & $(144) 84.7 \%$ & $(30) 78.9 \%$ & & \\
Physical \& mental exhaustion & & & \\
\hline
\end{tabular}




\begin{tabular}{lllll}
\hline \multirow{2}{*}{ Menopausal Symptoms } & Level of Physical Activities & & \multirow{2}{*}{ Chi-Square Test } & \multirow{2}{*}{ P-Value } \\
\cline { 2 - 3 } & Mild n=170 (82\%) & Moderate n=38 (18\%) & & 0.837 \\
\hline Urogenital symptoms: & $(90) 52.9 \%$ & $(17) 44.7 \%$ & 0.811 & 0.360 \\
Sexual problems & $(150) 88.2 \%$ & $(33) 86.8 \%$ & 0.473 & 0.811 \\
Bladder problem & $(87) 51.2 \%$ & $(17) 44.7 \%$ & 0.473 \\
Vaginal dryness & &
\end{tabular}

Table 6: The data were further analyzed to explore the relationship between menopausal symptoms and demographic characteristics of participants. It is observed from table 6 that the Body Mass Index (BMI) and the somatic symptoms provides a high statistical significance with $\mathrm{p}$ value of 0.001 . When data analyzed for the marital status, illustrates statistical significance with the somatic (P $=0.013)$ and urogenital symptoms $(\mathrm{P}=0.015)$. A high statistical significance was also observed for occupation, smoking, low fat consumption and consumption of tea/coffee ( $\mathrm{P}=0.001, \mathrm{P}=0.018, \mathrm{P}=0.016$ and $\mathrm{P}=0.028$ respectively) with the related symptoms of somatic category.

Table 6. Relationship between Menopausal Symptoms \& Demographic Characteristics of Participants.

\begin{tabular}{|c|c|c|c|}
\hline \multirow{2}{*}{ Demographic Characteristics } & \multicolumn{3}{|c|}{ Menopausal Symptoms (Mean + SD) } \\
\hline & Somatic symptoms & Psychological symptoms & Urogenital symptoms \\
\hline \multicolumn{4}{|l|}{ Marital status: } \\
\hline Single & $1.1 \pm 0.8$ & $1.5 \pm 0.4$ & $1.8 \pm 1.4$ \\
\hline Married & $1.1 \pm 0.5$ & $1.2 \pm 0.6$ & $1.1 \pm 0.7$ \\
\hline Widow & $1.3 \pm 0.6$ & $1.2 \pm 0.6$ & $1.2 \pm 0.6$ \\
\hline Divorced & $1.1 \pm 0.6$ & $1.3 \pm 0.5$ & $1.8 \pm 1.2$ \\
\hline \multirow{2}{*}{ Test value } & $F=3.71$ & $\mathrm{~F}=0.575$ & $F=3.547$ \\
\hline & $\mathrm{P}=0.013^{*}$ & $\mathrm{P}=0.632$ & $\mathrm{P}=0.015^{*}$ \\
\hline \multicolumn{4}{|l|}{ Nationality: } \\
\hline Saudi & $1.1 \pm 0.5$ & $1.2 \pm 0.6$ & $1.2 \pm 0.7$ \\
\hline Non-Saudi & $1.0 \pm 0.5$ & $1.1 \pm 0.6$ & $1.1 \pm 0.7$ \\
\hline & $\mathrm{t}=1.351$ & $\mathrm{t}=1.451$ & $\mathrm{t}=0.595$ \\
\hline Test value & $\mathrm{P}=0.178$ & $\mathrm{P}=0.148$ & $\mathrm{P}=0.553$ \\
\hline \multicolumn{4}{|l|}{ Educational level: } \\
\hline Illiterate & $1.2 \pm 0.5$ & $1.3 \pm 0.6$ & $1.1 \pm 0.7$ \\
\hline Primary School & $1.2 \pm 0.6$ & $1.2 \pm 0.5$ & $1.2 \pm 0.8$ \\
\hline Intermediate school & $1.1 \pm 0.5$ & $0.9 \pm 0.5$ & $1.3 \pm 0.5$ \\
\hline High school & $0.9 \pm 0.4$ & $1.1 \pm 0.6$ & $1.3 \pm 0.6$ \\
\hline University or higher & $1.0 \pm 0.5$ & $1.2 \pm 0.7$ & $0.9 \pm 0.7$ \\
\hline \multirow{2}{*}{ Test value } & $\mathrm{F}=1.041$ & $\mathrm{~F}=1.713$ & $\mathrm{~F}=1.031$ \\
\hline & $\mathrm{P}=0.395$ & $\mathrm{P}=0.133$ & $P=0.401$ \\
\hline \multicolumn{4}{|l|}{ Occupation: } \\
\hline Employed & $0.9 \pm 0.4$ & $1.1 \pm 0.5$ & $1.2 \pm 0.8$ \\
\hline Housewife & $1.2 \pm 0.5$ & $1.2 \pm 0.6$ & $1.2 \pm 0.7$ \\
\hline Retiree & $1.2 \pm 0.6$ & $1.2 \pm 0.5$ & $1.2 \pm 0.6$ \\
\hline \multirow{2}{*}{ Test value } & $\mathrm{F}=6.818$ & $F=0.200$ & $\mathrm{~F}=0.062$ \\
\hline & $\mathrm{P}=0.001 *$ & $\mathrm{P}=0.819$ & $\mathrm{P}=0.940$ \\
\hline \multicolumn{4}{|l|}{ BMI: } \\
\hline Underweight & $0.6 \pm 0.2$ & $0.8 \pm 0.5$ & $0.9 \pm 0.7$ \\
\hline Normal & $1.1 \pm 0.4$ & $1.2 \pm 0.6$ & $1.2 \pm 0.7$ \\
\hline Overweight & $1.2 \pm 0.6$ & $1.2 \pm 0.5$ & $1.2 \pm 0.9$ \\
\hline Obese & $2.3 \pm 0.6$ & $1.4 \pm 0.4$ & $1.0 \pm 0.7$ \\
\hline \multirow[b]{2}{*}{ Test value } & $F=4.641$ & $\mathrm{~F}=1.752$ & $\mathrm{~F}=0.506$ \\
\hline & $\mathrm{P}=0.001^{*}$ & $\mathrm{P}=0.140$ & $\mathrm{P}=0.732$ \\
\hline \multicolumn{4}{|l|}{ Alcohol use: } \\
\hline Yes & $1.2 \pm 0.7$ & $1.4 \pm 0.4$ & $1.2 \pm 0.9$ \\
\hline No & $1.1 \pm 0.5$ & $1.2 \pm 0.6$ & $1.1 \pm 0.7$ \\
\hline \multirow{2}{*}{ Test value } & $\mathrm{t}=0.122$ & $\mathrm{t}=1.042$ & $\mathrm{t}=0.51$ \\
\hline & $\mathrm{P}=0.903$ & $\mathrm{P}=0.299$ & $\mathrm{P}=0.960$ \\
\hline \multicolumn{4}{|l|}{ Smoking: } \\
\hline Never & $1.2 \pm 0.5$ & $1.2 \pm 0.6$ & $1.2 \pm 0.7$ \\
\hline Past smoker & $1.0 \pm 0.4$ & $1.0 \pm 0.6$ & $1.1 \pm 0.6$ \\
\hline Current smoker & $0.6 \pm 0.3$ & $0.8 \pm 0.6$ & $0.7 \pm 0.7$ \\
\hline \multirow{2}{*}{ Test value } & $F=4.108$ & $F=2.417$ & $F=2.368$ \\
\hline & $\mathrm{P}=0.018^{*}$ & $\mathrm{P}=0.092$ & $\mathrm{P}=0.096$ \\
\hline \multicolumn{4}{|l|}{ Eating fresh fruits \& vegetables: } \\
\hline Yes & $1.1 \pm 0.5$ & $1,2 \pm 0.6$ & $1.2 \pm 0.7$ \\
\hline No & $1.3 \pm 0.6$ & $1.2 \pm 0.7$ & $1.1 \pm 0.6$ \\
\hline \multirow{2}{*}{ Test value } & $\mathrm{t}=1.092$ & $t=0.304$ & $t=0.439$ \\
\hline & $\mathrm{P}=0.276$ & $\mathrm{P}=0.762$ & $\mathrm{P}=0.661$ \\
\hline
\end{tabular}




\begin{tabular}{llll}
\hline \multirow{2}{*}{ Demographic Characteristics } & Menopausal Symptoms (Mean + SD) & & Urogenital symptoms \\
\cline { 2 - 4 } & Somatic symptoms & Psychological symptoms & $1.2 \pm 0.7$ \\
\hline Eating low fat diet: & $1.1 \pm 0.5$ & $1.2 \pm 0.5$ & $1.1 \pm 0.6$ \\
Yes & $1.3 \pm 0.5$ & $1.3 \pm 0.6$ & $\mathrm{t}=0.946$ \\
No & $\mathrm{t}=2.437$ & $\mathrm{t}=1.236$ & $\mathrm{P}=0.345$ \\
Test value & $\mathrm{P}=0.016^{*}$ & $\mathrm{P}=0.218$ & $1.2 \pm 0.7$ \\
Tea/coffee consumption: & & $1.2 \pm 0.5$ & $1.1 \pm 0.7$ \\
Yes & $1.2 \pm 0.5$ & $1.2 \pm 0.6$ & $\mathrm{t}=1.512$ \\
No & $1.0 \pm 0.4$ & $\mathrm{t}=0.267$ & $\mathrm{P}=0.132$ \\
Test value & $\mathrm{t}=2.224$ & $\mathrm{P}=0.790$ & \\
\hline
\end{tabular}

*Statistically significant

\section{Discussion}

Physical activity may be an effective way of preventing or attenuating menopause-related symptoms, it has been shown to improve the quality of life in menopausal women [6. However, this study was designed on the context of limited researches on menopausal symptoms and its association with physical activity in the Kingdom of Saudi Arabia, especially in the Eastern region.

Therefore, in this study the association between physical activities and menopausal symptoms in women under three categories (somatic, psychological and urogenital symptoms) according to MRS was assessed at KFHU in Al-Khobar city.

The present study shown that, most of participants were Saudi nationals $(77.4 \%)$ and hence the study revealed the real picture of menopausal women in Al-Khobar City-Eastern region-Saudi Arabia. Moreover, participants mean age was $61.7 \pm 8.9$ years' old $(69.2 \%)$ of the study subjects were under the normal BMI compared to underweight $(2.4 \%)$, overweight $(22.1 \%)$, or obese women $(6.3 \%)$, which helps to eliminate undesirable results due to the impact of overweight on endocrine system especially estrogen and progestogen which influence body weight, as stated by Aida AlDughaither, Hind AlMutairy \&Mohammed AlAteeq] (2015) [20].

In addition, the results of the present study revealed that the participants consume fruits and vegetables (91.3\%), which also illustrate a healthy and desirable dietary pattern of participants. This nearly agrees with the findings of a study conducted by Hong et al, (2017) [20], who reported that greater dietary intake of fruits and vegetables may protect against the risk of metabolic syndrome, particularly in postmenopausal women.

Further, $78.8 \%$ of participants follow a low-fat diet which may also be a positive factor on reducing the implications of other risk factors in this study. This is consistent with a study results in a trial conducted earlier to assess the effect of a low-fat dietary pattern on breast cancer suggested that hot flashes may identify a subgroup of postmenopausal women whose risk of invasive breast cancer might be reduced with the adoption of a low-fat eating pattern [21].

Distribution of menopausal symptoms under somatic subscale based on MRS were considered, which indicates that the joint and muscular discomfort is the most felt menopausal symptom on different degree (mild, moderate or severe). This is a most common problem raised by many of the aged women and hence this may be an overestimation. However, other studies illustrate that menopause is associated with cartilage degeneration of knee joint. After menopause, cartilage showed progressive severe degeneration that occurred in the first 25 years of menopause, suggesting estrogen deficiency might be a risk factor of cartilage degeneration of the knee joint [22-24]. Even though, hot flush/sweating, heart discomfort and sleep problems were also reported at mild and moderate levels with comparatively of less number of cases, while joint and muscular discomfort dominates.

However, the distributions of psychological symptoms like depressive mood, irritability, anxiety and physical and mental exhaustion were almost common to all the participants. Whereas, bladder problem was quite common among the women, only a few $(11.5 \%)$ of them reported it is not a problem. In agreement with Jones et al, (2016) [25] who reported that bladder symptoms were associated with reproductive stage as women in late reproductive stage were more likely to experience nocturia and incontinence than those in menopause transition and the higher rates of nocturia and incontinence in late reproductive stage are intriguing.

In addition to distribution of symptoms, the study explored the prevalence of menopausal symptoms. Joint and muscular discomfort is identified as the symptom with highest prevalence $(95.2 \%)$. The very high prevalence of the previous stated symptom may be because of the age induced changes in the joints and muscles. After a middle age many irrespective of the gender may report with the same complaint.

Prevalence of almost all menopausal symptoms was higher, above $50 \%$ ranging from $50.5 \%$ to $95.2 \%$. There are many studies which agree to the findings of this study as the most frequent five symptoms among the investigated Chinese women were fatigue, insomnia, irritability, palpitations, depression, nearly the same in perimenopausal and postmenopausal women [26].

An Egyptian study also indicates that postmenopausal women have higher prevalence of menopausal symptoms that significantly affect their quality of life more than pre- and perimenopausal women and those in the transition period (perimenopausal) have higher prevalence of psychological symptoms with higher impact on their psychological welfare [27]. 
Level of physical activities of the participants in this study was considerably less, may be because majority of the participants were housewives, unemployed or retired. The study also looked into the level of physical activity of participants and prevalence of menopausal symptoms, we observed that only hot flush/sweating and depressive mood is related with mild to moderate physical activity and providing significant results. Similar to our findings, IMEO et al (2017) [28] in their studies concluded that for middle age women tend to reduce their menopausal symptoms through increasing their physical activity. Their findings also supported the feasibility of a 3-month Web-based intervention for menopausal symptom management among Asian American midlife women and the preliminary efficacy of the program in increasing their physical activity.

Yet another study indicates that an increase in BMI was associated with an increased severity of vasomotor symptoms. The prevalence and severities of shoulder stiffness considered a characteristic symptom in Japanese women were high. Increased BMI was shown to be associated with a higher severity of vasomotor symptoms, joint pain, nervousness, and urinary symptoms [29].

\section{Conclusion}

1. The association of physical activities and severity of menopausal symptoms among menopausal women was assessed. In conclusion, the present study evidenced that more than half of menopausal women (53.4\%) were in the normal menopausal age with a mean menopausal age of participants $47.7(\mathrm{SD} \pm 4.5)$ and most of them were with a normal BMI $(69.2 \%)$. The study signifies that the prevalence of joint and muscular discomfort was the highest $(95.2 \%)$ among the four somatic menopausal symptoms, followed by bladder problems was the highest $(88.5 \%)$ among urogenital symptoms. However, the physical and mental exhaustions were the highest among psychological subscales with $84.1 \%$ of the participants, followed by depressive mood $(79.3 \%)$, sleep problems $(77.8 \%)$ and irritability (68.2\%).

2. The study also pointed out to most of the participants of the study $(82 \%)$ were more likely to do only mild exercise and only two symptoms namely hot flush/sweating from somatic symptoms and depressive mood under psychological symptoms demonstrated statistical significance with $\mathrm{p}$ values $0.002 \& 0.029$ respectively. This indicates that these two symptoms were high among those doing mild exercise, whereas the menopausal symptoms were low with those doing moderate exercise. However, there was no statistical significance between the remaining symptoms and the level of physical activities.

\section{Recommendations}

1. Forthcoming work should be conducted to better understand the unmet health needs of Saudi women entering or experiencing menopause.

2. Integrating awareness programs on physical activity to a study group and its comparison with a control group could provide insight into the outcome of awareness and effect of physical activity on reducing the severity of the menopausal symptoms.

3. Further research can be conducted to different urban and rural populations to investigate a greater sample size with multiple hospitals in the Eastern Region would give significant results on severity, perception and the effect of physical activity on menopausal symptoms.

4. An epidemiological cross-sectional community-based study will be more beneficial to understand the prevalence and severity of menopausal symptoms on a larger population.

\section{Limitations of the Study}

1. The research was conducted in King Fahd Hospital of the University and the data was only from the patients who reported to the hospital. Hence, the result may not provide a broad picture of the general population.

2. Short period of data collection that lead to small sample size.

3. The physical activity was measured only by self-report and included estimates for leisure-time activities only, without corroboration of other physical parameters such as fitness or body composition.

\section{References}

[1] A־gil. A, Abıke. F, Das, kapan. A, Alaca. R and Tuzun. H, (2010). Short-Term Exercise Approaches on Menopausal Symptoms, Psychological Health and Quality of Life in Postmenopausal Women. Obstetrics and Gynecology International, Article ID 274261, p.7.

[2] Takahashi TA, Johnson KM. (2015). Menopause. Med Clin North Am, 99: 521 534. Teede HJ, Lombard C, Deeks AA. (2010). Obesity, metabolic complications and the menopause: an opportunity for prevention. Climacteric. 13 (3): 203-9.

[3] Harlow SD, Gass M, Hall JE, et al. (2012). STRAW 10 Collaborative Group: Executive summary of the Stages of Reproductive Aging Workshop: addressing the unfinished agenda of staging reproductive aging. Menopause, 19: 387395 .

[4] Kim MJ, Yim G, Park HY. (2018). Vasomotor and physical menopausal symptoms are associated with sleep quality. PLoS One. 13 (2): e0192934.

[5] Al Dughaither, A., AlMutairy, H., \& AlAteeq, M. (2015). Menopausal symptoms and quality of life among Saudi women visiting primary care clinics in Riyadh, Saudi Arabia. International Journal of Women's Health, 7, 645-653. http://doi.org/10.2147/IJWH.S84709 
[6] Kim, M., Cho, J., Ahn, Y., Yim, G., \& Park, H. (2014). Association between physical activity and menopausal symptoms in perimenopausal women. BMC Women's Health, 14, 122. doi: http://dx.doi.org.library.iau.edu.sa/10.1186/14726874-14-122.

[7] Stojanovska L, Apostolopoulos V, Polman R \& Borkoles E. 2014: To exercise, or, not to exercise, during menopause and beyond. Maturitas. Volume 77, Issue 4, Pages 318-323.

[8] Physical Activity Guidelines Advisory Committee. 2008: Physical Activity Guidelines Advisory Committee Report. Washington, DC: U.S. Department of Health and Human Services.

[9] Godin G, Shephard RJ. (1985): A simple method to assess exercise behavior in the community. Canadian journal of applied sport sciences. 10 (3): 141-6.

[10] Villaverde-Gutiérrez C, Araújo E, Cruz F, Roa JM, Barbosa W, Ruíz-Villaverde G. 2006: Quality of life of rural menopausal women in response to a customized exercise programme. J Adv Nurs, 54: 11-19.

[11] McAndrew LM, Napolitano MA, Albrecht A, Farrell NC, Marcus BH, Whiteley JA. 2009: When, why and for whom there is a relationship between physical activity and menopause symptoms. Maturitas, 64: 119-125.

[12] Mirzaiinjmabadi K, Anderson D, Barnes M. 2006: The relationship between exercise, Body Mass Index and menopausal symptoms in midlife Australian women. Int $\mathrm{J}$ Nurs Pract, 12: 28-34.

[13] De Azevedo Guimarães AC, Baptista F. 2011: Influence of habitual physical activity on the symptoms of climacterium/menopause and the quality of life of middleaged women. Int J Womens Health, 3: 319-328.

[14] Skrzypulec V, Dabrowska J, Drosdzol A. 2010: The influence of physical activity level on.

[15] Chang, S. J., Chee, W., \& Im, E.-O. (2013). Menopausal symptoms and physical activity in multiethnic groups of midlife women: A secondary analysis. Journal of Advanced Nursing, 69 (9), 1953-1965. http://doi.org/10.1111/jan.12056 climacteric symptoms in menopausal women. Climacteric, 13: 355-361.

[16] Asghari M, Mirghafourvand M, Mohammad-AlizadehCharandabi S, MalakoutiJ, Nedjat S. (2017). Effect of aerobic exercise and nutrition educationon quality of life and early menopause symptoms: A randomized controlled trial. Women Health. 57 (2): 173-188.

[17] Ogwumike OO, Sanya AO, Arowojolu AO. (2011). Endurance exercise effect on quality of life and menopausal symptoms in Nigerian women. Afr J Med Med Sci. 40 (3): 187-95.
[18] Heinemann. L, (1990): BERLIN CENTER FOR EPIDEMIOLOGY AND HEALTH RESEARCH. Zegberlin. de. http://www.menopause-rating-scale.info/about.htm

[19] Aida AlDughaither, Hind AlMutairy, Mohammed AlAteeq. (2015). Menopausal symptoms and quality of life among Saudi women visiting primary care clinics in Riyadh, Saudi Arabia. International Journal of Women's Health. 7: 645-653.

[20] Hong SA, Kim MK (2017): Relationship between fruit and vegetable intake and the risk of metabolic syndrome and its disorders in Korean women according to menopausal status. Asia Pac J Clin Nutr.; 26 (3): 514-523.

[21] Caan BJ, Aragaki A, Thomson CA, Stefanick ML, Chlebowski R, Hubbell FA, Tinker L, Vitolins M, Rajkovic A, Bueche M, Ockene J. (2009): Vasomotor symptoms, adoption of a low-fat dietary pattern, and risk of invasive breast cancer: a secondary analysis of the Women's Health Initiative randomized controlled dietary modification trial. J Clin Oncol. 27 (27): 4500-7.

[22] Lou C, Xiang G, Weng Q, Chen Z, Chen D, Wang Q, Zhang D, Zhou B, He D, Chen H. (2016): Menopause is associated with articular cartilage degeneration: a clinical study of knee joint in 860 women. Menopause.; 23 (11): 1239-1246.

[23] Fenton A, \& Panay N. (2016): Estrogen, menopause and joints. Climacteric. 19 (2): 107-8.

[24] Gerber LM, Chiu YL, Verjee M, Ghomrawi H. (2016): Health-related quality of life in midlife women in Qatar: relation to arthritis and symptoms of joint pain. Menopause. 23 (3): 324-9.

[25] Jones HJ, Huang AJ, Subak LL, Brown JS, Lee KA. (2016): Bladder Symptoms in the Early Menopausal Transition. J Womens Health (Larchmt). 25 (5): 457-63.

[26] Ruan X, Cui Y, Du J, Jin F, Mueck AO. (2017): Prevalence of climacteric symptoms comparing perimenopausal and postmenopausal Chinese women. J Psychosom Obstet Gynaecol. 38 (3): 161-169.

[27] Ibrahim ZM, Sayed Ahmed WA, El-Hamid SA. (2015): Prevalence of menopausal related symptoms and their impact on quality of life among Egyptian women. Clin Exp Obstet Gynecol. 42 (2): 161-7.

[28] IMEO, Kim S, Ji X, Park S, Chee E, Chee W, Tsai HM. (2017): Improving menopausal symptoms through promoting physical activity: a pilot Web-based intervention study among Asian Americans. Menopause. 24 (6): 653-662.

[29] Yokota M, Makita K, Hirasawa A, Iwata T, Aoki D. (2016): Symptoms and effects of physical factors in Japanese middleaged women. Menopause. 23 (9): 974-83. 